\title{
LOW-FLOW ANESTHESIA TECHNIQUE REDUCES EMERGENCE AGITATION IN PEDIATRIC PATIENTS UNDERWENT GENERAL ANESTHESIA
}

\author{
CHRISTOPHER RYALINO*, TJOKORDA GDE AGUNG SENAPATHI, ADINDA PUTRA PRADHANA, \\ ANDRIAN YADIKUSUMO
}

Department of Anesthesiology, Pain Medicine, and Intensive Care, Udayana University, Bali, Indonesia. Email: ryalino@unud.ac.id

Received: 11 February 2019, Revised and Accepted: 29 March 2019

\section{ABSTRACT}

Objectives: This study was designed to see the risk factors that contribute to emergence agitation (EA) and also to know the effectiveness of low-flow (LF) anesthesia technique in EA in pediatric patients.

Methods: A total of 200 pediatric patients aged 6 months- 6 years underwent surgery with general anesthesia were divided into two groups. The high-flow (HF) group was maintained with $5 \mathrm{l}$ fresh gas flow (FGF), and the LF group was maintained with 500 ml FGF. The outcome was measured after the surgery was completed on Face, Legs, Activity, Cry, and Consolability and pediatric anesthesia emergence delirium (PAED) scores. Agitation defined in PAED score $\geq 10$, and no agitation defined in PAED score $<10$.

Results: EA incidence in the HF group was higher compared to the LF group (59.5 vs. 4.7\%, p<0.001). HF anesthesia technique was a single risk factor for agitation event, whereas LF anesthesia may prevent EA incidence until up to $92.7 \%$.

Conclusion: LF anesthesia reduced agitation incidences. The effectiveness of LF was $92.7 \%$ in reducing the incidence of agitation. HF anesthesia was the main risk factor for agitation incidences.

Keywords: Post-anesthesia agitation, Emergence delirium, Sevoflurane, Pediatric

(C) 2019 The Authors. Published by Innovare Academic Sciences Pvt Ltd. This is an open access article under the CC BY license (http://creativecommons. org/licenses/by/4. 0/) DOI: http://dx.doi.org/10.22159/ajpcr.2019.v12i5.32508

\section{INTRODUCTION}

Emergenceagitation(EA)isa commonprobleminpediatricanesthesia[1]. It is defined as a consciousness dissociation that characterized when the patient is not consolable, uncooperative, irritable, destructive, crying, and unable to recognize people that are familiar in their daily life, on the emergence of anesthesia. Some risk factors known for this condition are rapid emergence, use of volatile agents, post-operative pain, choking sensation, and patient's psychological condition. It is a self-limiting condition that occurs for 5-15 min. The incidence rate varies from $10 \%$ to $80 \%$ among all children underwent surgery with general anesthesia and in some cases requires some pharmacological interventions [2]. Some agents used for eliminating this condition are hypnotics-sedative drugs (e.g., midazolam, flumazenil, and propofol) and analgesics such as opioids and NSAID [3].

The use of volatile anesthesia in pediatric patients, in both induction and maintenance phases, is still a common practice [4-6]. Sevoflurane is the most used volatile agent despite its potency in producing EA $[1,2,7]$. This is due to its pharmacological content that binds in $\mathrm{GABA}_{\mathrm{A}}$ receptors in $\alpha$ and $\gamma$ subsegments [8].

Low-flow (LF) anesthesia was developed in modern medicine era. It was introduced by Foldes using a liter per minute anesthesia. Virtue then introduced minimal flow anesthesia with a $500 \mathrm{ml} / \mathrm{min}$ anesthesia in 1974 [9]. A semi-closed breathing system, a fresh gas flow (FGF) that is less than the patient's minute volume, and a $\mathrm{CO}_{2}$ absorbent system are some requirements for LF anesthesia [10-12]. Some advantages in this technique are rapid emergence, diminished post-anesthesia agitation, reduction in volatile agents used, and eco-green anesthesia $[11,12]$. Postoperative nausea and vomiting was also reduced in LF anesthesia [13].

The goal of this study is to know the effectiveness of LF anesthesia technique to reduce EA in pediatric patients.

\section{METHODS}

This is a prospective, single-blind study that was approved by the Committee of Ethical Study of Sanglah General Hospital in Denpasar, Indonesia. All subjects involved in this study have provided written consent signed by their parents or legal guardians. Inclusion criteria were pediatric patients aged 6 months -6 years old with the American Society of Anesthesiologist (ASA) physical Status I or II who underwent an elective surgical procedure. Exclusion criteria were hemostatic profile abnormality, liver function abnormality, and any previous history of the psychological disorder. Subjects were divided into either the LF anesthesia group or high-flow (HF) anesthesia group by random order. All surgeries were performed in the first round to reduce patient bias.

Premedications used for both groups were midazolam $0.1 \mathrm{mg} / \mathrm{kg}$ and ketamine 2-3 $\mathrm{mg} / \mathrm{kg}$ intramuscularly before the delivery from preparation room to operating theater. Standard ASA monitoring is used for this study. After IV line is established, we administered $2 \mathrm{mcg} / \mathrm{kg}$ of fentanyl and $0.5 \mathrm{mg} / \mathrm{kg}$ of atracurium for analgesic and facilitating direct laryngoscopic intubation.

In the LF group, anesthesia was maintained with 1 vol\% sevoflurane in $0.5 \mathrm{l} / \mathrm{min}$ FGF. In the HF group, anesthesia was maintained with $1 \mathrm{vol} \%$ sevoflurane in $5 \mathrm{l} / \mathrm{min}$ FGF. After the surgery, the volatile gas flow was stopped, and FGF was set for both groups to $5 \mathrm{l} / \mathrm{min}$ to facilitate the washout process. The emergence time was recorded for the purpose of this study.

Patients were moved to the recovery room after the Aldrete's score is more than 9. They were then observed for Pediatric Anesthesia Emergence Delirium (PAED) score; Face, Legs, Activity, Cry, and Consolability (FLACC) score; and vital signs for $30 \mathrm{~min}$, where the numbers were recorded in $10 \mathrm{~min}$ interval. The observation was carried 
out directly by researchers to minimize inter-rater bias. Agitation score recorded using the PAED score. EA is defined as PAED score $\geq 10$. If EA occurs, rescue medications of fentanyl $0.1 \mathrm{mcg} / \mathrm{kg}$ and propofol $0.1 \mathrm{mg} / \mathrm{kg}$ were administrated.

The incidence and severity of EA including categorical data such as gender, choice of anesthesia, and FLACC score were compared using the Chi-square test or Fisher's exact test as appropriate. Age, body weight, emergence time, sevoflurane consumption, and duration of anesthesia were analyzed by the independent t-test or non-parametric MannWhitney U-test-Wilcoxon rank-sum test as appropriate. $\mathrm{p}<0.05$ was considered statistically significant.

\section{RESULTS}

A total of 200 subjects were eligible for this study. None were excluded or dropped out. Table 1 shows demographic data in two groups. No statistically significant differences were found in all variables.

Table 2 shows a comparison of sevoflurane consumption and emergence time between two groups. No significant findings in emergence between the two groups. Sevoflurane consumption per min was higher in HF groups compared to the LF group (18 [13] vs. 40 [25.5], p<0.001).

Table 3 shows a comparison of the FLACC score between two groups. No significant findings in this score in every time interval result ( 0 vs. $3, \mathrm{p}=0.223$ ). Moreover, Table 4 shows a comparison of agitation profile between two groups. Significant findings in agitation profile are seen in total incidence between the two groups ( $4.7 \%$ vs. $59.5 \%$, p $<0.001)$.

Table 5 shows a survival analysis for all risk factors to agitation incidence. The findings show that $\mathrm{HF}$ technique was the main risk factor to agitation incidences in the pediatric population $(\mathrm{p}<0.001)$.

Table 1: Demographic data

\begin{tabular}{lll}
\hline Variables & \multicolumn{2}{l}{ Treatment groups } \\
\cline { 2 - 3 } & $\begin{array}{l}\text { Low-flow } \\
\text { group } \mathbf{n = 1 0 6}\end{array}$ & $\begin{array}{l}\text { High-flow } \\
\text { group } \mathbf{n = 9 4}\end{array}$ \\
\hline Gender & $68(64.1)$ & $63(67.1)$ \\
$\quad$ Male, $\mathrm{n}(\%)$ & $38(35.8)$ & $31(32.9)$ \\
Female, $\mathrm{n}(\%)$ & $35.5(57)$ & $41.5(41)$ \\
Age in months, median (IQR) & $12(9.62)$ & $14(8.25)$ \\
Weight in kg, median (IQR) & $96.5(32.5)$ & $100(34.25)$ \\
Height in cm, median (IQR) & $61(57.5)$ & $58(61.7)$ \\
ASA physical status & $45(42.5)$ & $36(38.2)$ \\
$\quad$ ASA I, n (\%) & $02: 20(01: 23)$ & $01: 20(00: 57)$ \\
ASA II, n (\%) & & \\
Anesthesia time in hh:mm, & \\
median (IQR) & & \\
\hline IQR: Interquartile range, ASA: American Society of Anesthesiologist
\end{tabular}

Table 2: Comparison of sevoflurane consumption and emergence time

\begin{tabular}{llll}
\hline Variable & \multicolumn{2}{l}{$\begin{array}{l}\text { Treatment group, } \\
\text { median (IQR) }\end{array}$} & \multirow{2}{*}{ p-value $^{\mathbf{a}}$} \\
\cline { 2 - 3 } & $\begin{array}{l}\text { Low-flow } \\
\text { group } \\
\mathbf{n = 1 0 6}\end{array}$ & $\begin{array}{l}\text { High-flow } \\
\text { group } \\
\mathbf{n = 9 4}\end{array}$ & \\
\hline $\begin{array}{llll}\text { Sevoflurane } \\
\text { consumption (ml) }\end{array}$ & $18(13)$ & $40(25.5)$ & $<0.001$ \\
95\% CI & $18.1-21.6$ & $39.1-48.1$ & \\
$\begin{array}{l}\text { Emergence time (min) } \\
\text { 95\% CI }\end{array}$ & $5(4)$ & $9(5)$ & $<0.001$ \\
\hline
\end{tabular}

IQR: Interquartile range, CI: Confidence interval, ${ }^{a}$ Mann-Whitney U-test
From the survival analysis data, the effectivity for LF technique in reducing agitation incidences derived with the following formula:

$$
\mathrm{e}=1-\left\{\frac{1}{\text { AdjustedRR }}\right\} \times 100 \%=1-\left\{\frac{1}{13.711}\right\} \times 100 \%=92.7 \%
$$

This result means that LF anesthesia may reduce the incidence of EA up to $92.7 \%$.

\section{DISCUSSION}

EA in children is a multifactorial disease $[1,8]$. Objective measurement of agitation is difficult since there is no strict definition, and multiple different scales are currently in use [14]. In this study, agitation was measured using PAED scale ranging from 0 to 20 where a score of 10 or more indicates agitation [15].

Another potential problem in pediatric is to differentiate agitated behavior from pain behavior. Excluding postoperative pain as the main factor for agitation [14]. The result of this study was consistent with the previous study for comparison of EA after two different sevoflurane expelling methods in children [2]. That study reports the incidence of EA was higher in HF compared to LF expelling methods (30\% vs. 8\%).

Sevoflurane consumption in this study is consistent with the previous study conducted by Ryu et al. They reported longer anesthesia hours in LF technique for about $38.3 \%$ [16]. As for emergence time, the result was different where the emergence time in LF group was less than the HF group ( 5 vs. 9 min).

The risk analysis showed us that LF anesthesia technique was a factor that may prevent or reduce the incidence of EA. This result was in line to a case series that showed every case in laparoscopic procedure in infants and toddlers that used an LF technique did not show any signs of EA [11].

Table 3: Comparison of FLACC score

\begin{tabular}{llll}
\hline Variable & \multicolumn{2}{l}{ Treatment group } & p-value \\
\cline { 2 - 3 } & $\begin{array}{l}\text { Low-flow group } \\
\mathbf{n = 1 0 6}\end{array}$ & $\begin{array}{l}\text { High-flow group } \\
\mathbf{n = 9 4}\end{array}$ & \\
\hline FLACC score $>3$ & $0(0 \%)$ & $2(6.6 \%)$ & $0.223^{\mathrm{a}}$ \\
\hline FECC: Face
\end{tabular}

FLACC: Face, Leg, Activity, Cry, and Consolability, ${ }^{a}$ Chi-square test

Table 4: Comparison of agitation incidence

\begin{tabular}{llll}
\hline $\begin{array}{l}\text { Emergence } \\
\text { agitation }\end{array}$ & \multicolumn{2}{l}{ Treatment group } & p-value \\
\cline { 2 - 3 } & $\begin{array}{l}\text { Low-flow } \\
\text { group } \\
\mathbf{n = 1 0 6}\end{array}$ & $\begin{array}{l}\text { High-flow } \\
\text { group } \\
\mathbf{n = 9 4}\end{array}$ & \\
\hline Incidence & & & \\
$\quad$ Agitated (\%) & $5(4.7)$ & $56(59.5)$ & $<0.001^{\text {a }}$ \\
$\quad$ Not agitated (\%) & $101(95.3)$ & $38(40.5)$ & \\
\hline aChi-square test & & &
\end{tabular}

Table 5: Survival multivariable analysis for agitation incidences risk factor

\begin{tabular}{llll}
\hline Variable & Adjusted RR & $\mathbf{9 5 \%}$ CI & p-value \\
\hline High-flow anesthesia & 13.711 & $5.446-34.523$ & $<0.001$ \\
Emergence time & 0.973 & $0.914-1.036$ & 0.394 \\
Age (months) & 0.996 & $0.985-1.006$ & 0.420 \\
FLACC score & 0.753 & $0.426-1.331$ & 0.329 \\
\hline
\end{tabular}

RR: Risk ratio, CI: Confidence interval, FLACC: Face, Leg, Activity, Cry, and

Consolability, ${ }^{a}$ Cox proportional hazard regression test 


\section{CONCLUSION}

LF anesthesia technique for pediatrics surgery may reduce the incidence of EA. The effectiveness of LF technique was $92.7 \%$ in reducing the incidence of EA.

\section{DISCLOSURES}

This study was approved by the Ethical Research Committee of Udayana University/Sanglah General Hospital (Ethical clearance number 2331/ UN.14.2/KEP/2017). The study was funded by departmental resources. The authors report no conflicts of interest in this work.

\section{ACKNOWLEDGMENT}

The authors report no conflicts of interest.

\section{AUTHORS' CONTRIBUTIONS}

Ryalino coconceived the study and wrote the paper. Senapathi supervised the study. Pradhana analyzed the data. Yadikusumo designed the study, collected the data, and analyzed the data.

\section{REFERENCES}

1. Mason LJ. Pitfalls in Pediatric Anesthesia; 2016. Available from: http:// www.2.pedsanesthesia.org/meetings/2004winter/pdfs/mason_Pitfalls. pdf. [Last accessed on 2016 Oct 11].

2. Baum VC. Development and psychometric evaluation of the pediatric anesthesia emergence delirium scale. Surv Anesthesiol 2005;49:35-6.

3. Singh R, Sood N, Chatterji C, Kharbanda M, Mahajan V. Comparative evaluation of incidence of emergence agitation and post-operative recovery profile in paediatric patients after isoflurane, sevoflurane and desflurane anaesthesia. Indian J Anaesth 2012;56:156

4. Yang Y, Song T, Wang H, Gu K, Ma P, Ma X, et al. Comparison of two different sevoflurane expelling methods on emergence agitation in infants following sevoflurane anesthesia. Int J Clin Exp Med 2015; 8:6200-5.

5. Sarkate AP, Lokwani DK, Bahekar SS, Shinde DB. Synthesis and docking studies of 2-(nitrooxy) ethyl-4-(2-(substituted phenyl)-4(substitute dphenyl)-1h-imidazol-1-yl) benzoate as anti-inflammatory, analgesic and nitric oxide releasing agents. Int J Pharm Pharm Sci 2015;7:197-05

6. Muhammad JY. The effect of time influence on physiological parameters following ketamine and diazepam administeration in cats. Int J Pharm Pharm Sci 2015;8:363-6.

7. Russo H, Brès J, Duboin MP, Roquefeuil B. Pharmacokinetics of thiopental after single and multiple intravenous doses in critical care patients. Eur J Clin Pharmacol 1995;49:127-37.

8. Kim JH. Mechanism of emergence agitation induced by sevoflurane anesthesia. Korean J Anesthesiol 2011;60:73.

9. Rupp K, Holzki J, Fischer T, Keller C. Pediatric Anesthesia. Lübeck, Germany: Dräger Medizintechnik GmbH; 1999.

10. Baum JA, Aitkenhead AR. Low-flow anaesthesia. Anaesthesia 1995; 50:37-44.

11. Yadikusumo A, Senapathi TG, Dewi DA, Pradhana AP, Sumanti AF. Low flow practice for laparoscopic colorectal surgery in pediatric patients. Bali J Anesthesiol 2018;2:3-9.

12. Senapathi TG, Suarjaya IP, Pradhana AP, Makmur E. Low flow anesthesia will gain ERAS (enhanced recovery after surgery). Bali J Anesthesiol 2017;1:51-4.

13. Isik Y, Goksu S, Kocoglu H, Oner U. Low flow desflurane and sevoflurane anaesthesia in children. Eur J Anaesthesiol 2006;23:60-4.

14. Meyer RR, Münster P, Werner C, Brambrink AM. Isoflurane is associated with a similar incidence of emergence agitation/delirium as sevoflurane in young children? A randomized controlled study. Pediatr Anesthesia 2007; 17:56-60.

15. Stamper MJ, Hawks SJ, Taicher BM, Bonta J, Brandon DH. Identifying pediatric emergence delirium by using the PAED scale: A quality improvement project. AORN J 2014;99:480-94.

16. Ryu HG, Lee JH, Lee KK, Gil NS, Kim CS, Sim SE, et al. The effect of low fresh gas flow rate on sevoflurane consumption. Korean J Anesthesiol 2011;60:75. 